Gut and Liver, Vol. 11, No. 3, May 2017, pp. 426-433

\title{
Prevalence and Incidence of Depression during Interferon-Based Antiviral Therapy in Chronic Hepatitis C Patients in the Republic of Korea
}

Joo Yeong Baeg ${ }^{1}$, In Hee Kim², Seung Young Seo², Young Seok Kim${ }^{3}$, Eun Uk Jung ${ }^{4}$, Junhyeon $\mathrm{Cho}^{1}$, Jung Wha Chung ${ }^{1}$, Eun Sun Jang ${ }^{1}$, Jin Wook Kim ${ }^{1}$, and Sook-Hyang Jeong ${ }^{1}$

${ }^{\prime}$ Department of Internal Medicine, Seoul National University Bundang Hospital, Seoul National University College of Medicine, Seongnam, ${ }^{2}$ Department of Internal Medicine, Chonbuk National University Hospital, Chonbuk National University Medical School, Jeonju, ${ }^{3}$ Department of Internal Medicine, Soonchunhyang University College of Medicine, Bucheon, and ${ }^{4}$ Department of Internal Medicine, Inje University Busan Paik Hospital, Busan, Korea

Background/Aims: The association between depression and chronic hepatitis $\mathrm{C}$ virus (HCV) infection or pegylated interferon $\alpha$ and ribavirin therapy (PR therapy) has not been extensively studied in Korea. We aimed to clarify the prevalence of depression and its incidence during PR therapy in chronic hepatitis $\mathrm{C}(\mathrm{CHC})$ patients. Methods: In this prospective, multicenter study, $114 \mathrm{CHC}$ patients were screened for depression using two self-reported scales, the Beck Depression Inventory-I (BDI-I) and the Hospital Anxiety and Depression scale (HADS). The incidence of depression during PR therapy was evaluated in 62 patients who underwent PR therapy during the study period. Results: The prevalence of baseline depression was $17.5 \%$ according to the BDI-I score $\geq 10$ criterion and $4.4 \%$ according to the HADS-D score $\geq 8$ criterion in the $114 \mathrm{CHC}$ patients, and it was significantly associated with an unmarried state. During PR therapy, depression developed in $34.6 \%$ according to the BDI-I scale and $29.5 \%$ according to the HADS-D, which negatively affected sustained virologic response (SVR). Conclusions: The prevalence of depression in Korean $\mathrm{CHC}$ patients appears to be low compared to that in Western patients; however, its incidence during PR therapy (approximately 30\%) was similar to that of other populations, which led to a lower SVR rate. Active screening and multidisciplinary management of depression during PR therapy is warranted. (Gut Liver 2017;11:426-433)

Key Words: Hepacivirus; Depression; Interferons; Beck Depression Inventory-l; Hospital Anxiety and Depression scale

\section{INTRODUCTION}

Hepatitis C virus (HCV) infection is a global health problem that affects about 185 million people with an estimated prevalence of 2.8\%. ${ }^{1}$ Not only increasing mortality and morbidity of HCV-related advanced liver diseases, but also patient-reported outcomes, including quality of life or mental health status lead to a significant global disease burden.

Previous studies in Western countries showed that patients with chronic HCV infection were associated with high prevalence of psychiatric and neurologic abnormalities. Moreover, pegylated interferon $\alpha$ and ribavirin therapy (PR therapy) can induce depression so that uncontrolled pretreatment depression is a major contraindication of PR therapy in chronic hepatitis C (CHC) patients. ${ }^{2,3}$ Although direct acting antivirals are applied to CHC patients, PR therapy is still widely used in many Asian countries and resource-limited regions. ${ }^{4}$

The epidemiology and risk factors of HCV infection as well as sociocultural background related to mental health status vary in different global regions. For example, intravenous drug use (IVDU), which is closely related to psychiatric abnormalities per se, is the major risk factor for HCV infection in Western countries, ${ }^{5-7}$ whereas it is only a minor risk factor in South Korea., ${ }^{8,9}$ Because there was few data on depression in Korean CHC patients, this study aimed to prospectively evaluate the prevalence of depression and its incidence during PR therapy.

\footnotetext{
Correspondence to: Sook-Hyang Jeong

Department of Internal Medicine, Seoul National University Bundang Hospital, 82 Gumi-ro 173beon-gil, Bundang-gu, Seongnam 13620, Korea

Tel: +82-31-787-7034, Fax: +82-31-787-4052, E-mail: jsh@snubh.org

Received on May 10, 2016. Revised on September 2, 2016. Accepted on October 21, 2016. Published online March 24, 2017

pISSN 1976-2283 eISSN 2005-1212 https://doi.org/10.5009/gnl16242

Joo Yeong Baeg and In Hee Kim contributed equally to this work as first authors.

@ This is an Open Access article distributed under the terms of the Creative Commons Attribution Non-Commercial License (http://creativecommons.org/licenses/by-nc/4.0) which permits unrestricted non-commercial use, distribution, and reproduction in any medium, provided the original work is properly cited.
} 


\section{MATERIALS AND METHODS}

\section{Patients}

From July 2011 to September 2014, 114 patients with chronic HCV infection were prospectively enrolled in three university hospitals (Seoul National University Bundang Hospital [SNUBH], Chonbuk National University Hospital [CNUH], and Soonchunhyang University Bucheon Hospital [SUBH]). The prevalence of depression was assessed in the 114 patients, who were treatment naïve $(n=65)$ or had failed previous treatment $(n=49)$. Patients with hepatitis B virus or human immunodeficiency virus coinfection and those who received antiviral therapy other than PR therapy such as first generation protease inhibitors in clinical trial setting, were excluded from this study.

Among the 114 patients, 62 patients began PR therapy during the study period, and underwent serial evaluation of depressive symptoms during PR therapy. In 62 patients, baseline depression before PR therapy was found in 10 patients by the Beck Depression Inventory-I (BDI-I) scale, and one patient by the Hospital Anxiety and Depression Scale (HADS). Therefore, the incidence of depression during PR therapy was evaluated separately in the 52 patients by the BDI scale and 61 patients by the HADS-D.

Informed written consent was obtained from all participants after approval of the study protocol by the Institutional Review Boards of the three hospitals (B-1109-1136-008, SNUBH; 201202-015-009, CNUH; and 2011-1-093, SUBH), and this study was carried out in accordance with the Ethical Principles for Medical Research Involving Human Subjects outlined in the Helsinki Declaration in 1997 (revised in 2000).

\section{Screening of depression}

For screening of depression, two kinds of validated selfassessment scales, the BDI-I and the HADS, were used for each patient.

BDI-I is a 21-item measure in which items are rated on a 0 to 3 scale and summed for a total score of 0 to 63. Higher scores indicate a greater degree of depressive symptoms. ${ }^{10,11}$ The standardized range of BDI-I score adopted by Shin et al. ${ }^{12}$ for minimal depression was 0 to 9 ; mild depression, 10 to 15 ; moderate depression, 16 to 23, and severe depression, 24 to 63 .

HADS consists of 14 items measuring depression and anxiety. It is divided into an anxiety subscale (HADS-A) and a depression subscale (HADS-D), and it omits the somatic symptoms of depression and anxiety which are frequently present in medically ill patients. Using the most commonly used cutoff score of 8 , minimal depression was defined as a HADS score of 0 to 7 , mild as 8 to 10 , and moderate to severe depression as 11 to $21 .^{13}$

If severe depression developed according to either of the above 2 scales, antidepressants were prescribed or the patients were referred to psychiatrists. Separately from the depression scales, the other standardized questionnaire survey was carried out in each patient with the assistance of the research coordina- tors. The questionnaire included data on patient demographics (e.g., age, gender, and marital status), potential risk factors for HCV infection, use of alcohol and other psychoactive substances, current or past treatment for depression, past history of PR therapy for chronic HCV infection, and laboratory results.

\section{Statistical analysis}

Continuous variables were expressed as means \pm standard deviation, and continuous variables were compared by an independent t-test or nonparametric Mann-Whitney U-test. Categorical data were compared with the chi-square test or Fisher exact test. The cumulative incidence of depression during PR therapy was analyzed using the Kaplan-Meier method. A p-value of $<0.05$ was considered to indicate a statistically significant difference. Data were analyzed using SPSS for Windows version 22.0 (IBM Corp., Armonk, NY, USA).

\section{RESULTS}

\section{Patients characteristics}

The clinical characteristics of the 114 subjects are summarized in Table 1 , showing the mean age to be 54.7 years with a male gender in 55.3\%. They included 86 patients (75.4\%) with chronic hepatitis, 23 patients (20.2\%) with liver cirrhosis, and five patients (4.4\%) with hepatocellular carcinoma (HCC). In the cirrhosis and HCC patients, Child-Pugh class A and B were (92.9\%) and (7.1\%), respectively. Among them, only three patients (2.6\%) were past IVDUs, and four patients (3.5\%) had a past history of depression.

\section{The prevalence of baseline depression and its related factors in chronic HCV infected patients}

In the 114 patients, the prevalence of baseline depression was $17.5 \%(n=20)$ defined as BDI-I $\geq 10$, while it was $4.4 \%$ defined as HADS-D $\geq 8$. The prevalence of baseline depression according to the different cutoff levels of either BDI-I scale or HADS are summarized in Table 2. It shows that the prevalence of moderate to severe depression by $\mathrm{BDI} \geq 16$ was $7.9 \%$ with a higher rate in women than in men. However, by the HADS, anxiety was more prevalent than depression. The comparative features of the depressive patients (BDI-I $\geq 10$ ) and not-depressive patients (BDI-I <10) at enrollment are presented in Table 3, showing the unmarried state was significantly more common in depressive patients, while age, gender, education level, liver disease state, HCV genotype or other laboratory results were not different between the two groups. The prevalence of depression among chronic hepatitis, liver cirrhosis, and HCC subgroup was not significantly different.

\section{The incidence of depression during PR therapy}

After enrollment, the 62 patients who underwent PR therapy were serially evaluated by depressive screening during anti- 
Table 1. Baseline Characteristics of 114 Korean Patients with Chronic Hepatitis C Virus Infection

\begin{tabular}{|c|c|}
\hline Variable & Value \\
\hline Age, yr & $54.7 \pm 1.1$ \\
\hline Male sex & $63(55.3)$ \\
\hline BMI, $\mathrm{kg} / \mathrm{m}^{2}$ & $23.7 \pm 0.3$ \\
\hline$>25$ & $34(29.8)$ \\
\hline Education, $\geq$ high school $(\mathrm{n}=108)$ & $71(62.3)$ \\
\hline Marital status, married $(n=111)$ & $103(90.4)$ \\
\hline Current or former alcohol intake $(n=113)$ & $66(57.9)$ \\
\hline Current or former smoking & $55(48.2)$ \\
\hline Past history of intravenous drug use $(n=112)$ & $3(2.6)$ \\
\hline \multicolumn{2}{|l|}{ Liver disease diagnosis } \\
\hline Chronic hepatitis & $86(75.4)$ \\
\hline Liver cirrhosis & $23(20.2)$ \\
\hline Hepatocellular carcinoma & $5(4.4)$ \\
\hline \multicolumn{2}{|l|}{ Laboratory results } \\
\hline WBC, $\mathrm{mm}^{3}$ & $4,936.6 \pm 176.6$ \\
\hline Hemoglobin, g/dL & $13.8 \pm 0.2$ \\
\hline Platelet, $\times 1,000 / \mathrm{mm}^{3}$ & $163.0 \pm 5.8$ \\
\hline Albumin, g/dL & $4.2 \pm 0.3$ \\
\hline Total bilirubin, mg/dL & $1.0 \pm 0.4$ \\
\hline AST/ALT, IU/L & $65.8 \pm 4.5 / 69.7 \pm 6.1$ \\
\hline Prothrombin time, INR & $1.1 \pm 0.1$ \\
\hline Creatinine, $\mathrm{mg} / \mathrm{dL}$ & $1.0 \pm 0.2$ \\
\hline HCV RNA level, $\log _{10} I U / m L(n=105)$ & $5.43 \pm 1.33$ \\
\hline HCV genotype $1 /$ non-1 (n=99) & $42(42.4) / 57(57.6)$ \\
\hline History of past antiviral treatment* & $49(43.0)$ \\
\hline History of depression & $4(3.5)$ \\
\hline
\end{tabular}

Data are presented as mean \pm SD or number (\%).

BMI, body mass index; WBC, white blood cell; AST, aspartate aminotransferase; ALT, alanine aminotransferase; INR, international normalized ratio; $\mathrm{HCV}$, hepatitis $\mathrm{C}$ virus.

${ }^{*}$ Forty-nine patients did not achieve sustained virological response after previous pegylated interferon $\alpha$ and ribavirin combination therapy, and the remaining 65 patients did not undergo antiviral therapy. viral therapy. Among them, 52 patients were depression-free at pretreatment by the BDI-I scale, in whom depression (BDI-I score $\geq 10$ ) developed in 18 patients $(34.6 \%)$ during PR therapy. However, 61 patients were depression-free at pretreatment by the HADS-D, and of these 18 patients (29.5\%) developed depression during PR therapy. The changes of depression score for those patients who developed depression over the course of PR therapy in both BDI-I scale and HADS-D are presented in Fig. 1. The overall cumulative probability of depression development by BDI-I $\geq 10$ during antiviral therapy was $21.5 \%$ at 12 weeks and $38.3 \%$ at 36 weeks of treatment, while the cumulative probability using HADS-D $\geq 8$ was $21.5 \%$ at 12 weeks and $34.2 \%$ at 36 weeks of PR therapy (Fig. 2).

The patients who developed depression (BDI-I $\geq 10$ ) during PR therapy showed a significantly lower sustained virologic response (SVR) rate $(55.6 \%, 10 / 18)$ than $85.3 \%$ (29/34) than in the patients who did not develop depression (Table 4). Though the treatment discontinuation rate was higher in depression-developed patients (5/18), only one of the five patients discontinued due to depression, and the other four discontinued due to hematologic adverse events $(n=1)$, fatigue $(n=1)$, no early virologic response at 12 weeks of PR therapy $(n=2)$.

Among 10 patients who had pretreatment depression (BDII score $\geq 10$ ), three patients showed aggravation of depression, four patients remained in a stationary depression state, and the remaining three showed decreased BDI scores of $<10$ during PR therapy (Fig. 3). Antidepressive therapy was prescribed to two patients showing aggravated depression symptoms with BDII scores of 27 and 25, respectively, which recovered after PR therapy. Among seven patients who were evaluated after PR therapy, six recovered from depression while one patient remained at a posttreatment BDI-I score of 11.

\section{DISCUSSION}

This prospective, multicenter study demonstrated that the prevalence of depression was $17.1 \%$ by BDI-I $\geq 10$ or $4.4 \%$ by

Table 2. Prevalence of Depression in 114 Patients with Chronic Hepatitis C Virus Infection According to the BDI-I and HADS

\begin{tabular}{cccc}
\hline Depression screening tool and cutoff & Total $(\mathrm{n}=114)$ & Male $(\mathrm{n}=64)$ & Female $(\mathrm{n}=50)$ \\
\hline Depression defined as BDI-I score $\geq 10$ & $20(17.5)$ & $10(15.9)$ & $10(19.6)$ \\
Mild (BDI score, $10-15)$ & $11(9.6)$ & $7(11.1)$ & $4(7.8)$ \\
Moderate (BDI score, $16-23)$ & $8(7.0)$ & $1(3.2)$ & $6(11.8)$ \\
Severe (BDI score $>23)$ & $1(0.9)$ & $3(4.8)$ & - \\
Depression defined as HRDS-D $\geq 8$ & $5(4.4)$ & $5(7.9)$ & $2(3.9)$ \\
HADS-A score $\geq 8$ & $11(9.6)$ & $3(4.8)$ & $6(11.8)$ \\
HADS-T score $\geq 16$ & $5(4.4)$ & $2(3.9)$ \\
\hline
\end{tabular}

Data are presented as number (\%).

BDI-I, Beck Depression Inventory-I; HADS, Hospital Anxiety and Depression scale; HADS-D, HADS-Depression; HADS-A, HADS-Anxiety; HADST, HADS-Total. 
Table 3. Comparison of Clinical Variables between Patients with a Positive Screen for Depression (BDI-I $\geq 10)$ and Patients with BDI-I $<10$

\begin{tabular}{|c|c|c|c|}
\hline Variable & $\begin{array}{l}\text { Depressive patients } \\
(\mathrm{BDI}-\mathrm{I} \geq 10, \mathrm{n}=20)\end{array}$ & $\begin{array}{l}\text { Not-depressive patients } \\
\quad(B D I-I<10, n=94)\end{array}$ & p-value \\
\hline Age, yr & $55.1 \pm 14.1$ & $54.7 \pm 10.6$ & 0.811 \\
\hline Male sex & $10(50.0)$ & $53(56.4)$ & 0.628 \\
\hline BMI, $\mathrm{kg} / \mathrm{m}^{2}$ & $22.7 \pm 1.9$ & $23.9 \pm 3.1$ & 0.113 \\
\hline$>25$ & $3(15.0)$ & $31(33.0)$ & 0.177 \\
\hline Education, $\geq$ high school & $11(57.9)$ & $60(67.4)$ & 0.436 \\
\hline Marital status, married & 15 (78.9) & $88(95.7)$ & 0.028 \\
\hline Current or former alcohol intake & $13(65.0)$ & $53(57.0)$ & 0.620 \\
\hline Current or former smoking & $10(50.0)$ & $45(47.9)$ & 1.000 \\
\hline History of intravenous drug use & $2(10.0)$ & $1(1.1)$ & 0.082 \\
\hline Past history of depression & $2(10.0)$ & $2(2.1)$ & 0.141 \\
\hline Chronic hepatitis in diagnosis & $14(70.0)$ & $72(76.6)$ & 0.571 \\
\hline HCV genotype 1 & $11(61.1)$ & $46(56.8)$ & 0.797 \\
\hline Previous antiviral treatment & $9(41.5)$ & $38(45.0)$ & 0.807 \\
\hline WBC, $\mathrm{mm}^{3}$ & $4,802.1 \pm 1,896.1$ & $4,965.8 \pm 1,872.7$ & 0.750 \\
\hline Hemoglobin, g/dL & $13.2 \pm 1.7$ & $13.9 \pm 1.8$ & 0.135 \\
\hline Platelet, $\times 1,000 / \mathrm{mm}^{3}$ & $157.6 \pm 68.3$ & $164.2 \pm 59.8$ & 0.624 \\
\hline Prothrombin time, INR & $1.1 \pm 1.2$ & $1.1 \pm 1.1$ & 0.799 \\
\hline Albumin, $\mathrm{g} / \mathrm{dL}$ & $4.2 \pm 0.5$ & $4.2 \pm 0.3$ & 0.672 \\
\hline Total bilirubin, mg/dL & $0.96 \pm 0.4$ & $0.96 \pm 0.4$ & 0.964 \\
\hline Creatinine, $\mathrm{mg} / \mathrm{dL}$ & $1.1 \pm 0.6$ & $1.1 \pm 1.8$ & 0.623 \\
\hline HCV RNA, $\log _{10} \mathrm{IU} / \mathrm{mL}$ & $5.68 \pm 1.17$ & $5.37 \pm 1.37$ & 0.432 \\
\hline AST, IU/L & $63.4 \pm 33.1$ & $66.3 \pm 51.0$ & 0.646 \\
\hline ALT, IU/L & $81.8 \pm 84.1$ & $67.1 \pm 60.2$ & 0.235 \\
\hline
\end{tabular}

Data are presented as mean \pm SD or number $(\%)$.

BDI-I, Beck Depression Inventory-I; BMI, body mass index; HCV, hepatitis C virus; WBC, white blood cell; INR, international normalized ratio; AST, aspartate aminotransferase; ALT, alanine aminotransferase.

HADS-D in chronic HCV-infected Korean patients, in whom a history of IVDU was only $2.5 \%$, and baseline depression was related to an unmarried state. During PR therapy, 34.6\% and 29.5\% of depression-free patients at pretreatment developed depression, by BDI-I $\geq 10$ and by HADS-D, respectively. Those who develop depression showed a significantly lower SVR rate and higher discontinuation of PR therapy than those who did not develop depression. Only two patients required antidepressant therapy during PR therapy and most of them recovered from depression after therapy, while one had persistent depression 6 months after the completion of PR therapy.

According to the Korea National Health \& Nutrition Examination Survey 2014 using Patient Health Questionnaire 9 (PHQ9) $\geq 10$, the prevalence of depression in the general population of Korea was 8.8\% in women and 4.3\% in men ( $\geq 19$ years old). In our study, the prevalence rate of depression by BDI-I in CHC patients was 19.2\% in women and 15.5\% in men, which seems to be higher than in general population of Korea, especially in men, though different screening tools and population characteristics did not permit direct comparison.
The prevalence of depression in chronic HCV-infected patients has been reported as 29.7\% in a large American cohort $(n=4,781)$ with a history of IVDU in $51.4 \%$ showing higher prevalence than the approximately $9 \%$ in general population using PHQ-8 (PHQ-8) with a cutoff score $\geq 10$, ${ }^{7}$ which was similar to the other study results. ${ }^{5,14}$ According to the data from the National Health and Nutrition Examination Survey (2005 to 2010, $n=10,231$ ), CHC was independently associated with depression, while chronic hepatitis B was not, in which depression prevalence by PHQ-9 in HCV patients was 54.6\% including major depressive disorder in $11.4 \% 0^{5,15-18}$ In Australian CHC patients $(\mathrm{n}=395)$, depression prevalence by HADS-D $\geq 8$ was $27 \%$, which was 2.4 times higher than community norms and was related to an unmarried state. ${ }^{6}$ In a Japanese national survey, patientreported depression rate was 7.1\%. However, data from Asian countries on the prevalence of depression in $\mathrm{CHC}$ patients are scarce, while a high prevalence (51.6\%) of depression by BDI-II was reported in 67 Chinese IVDUs. ${ }^{19}$

The depression prevalence in our patients seemed to be lower than in Western countries. Though the reason is not clear, the 
A

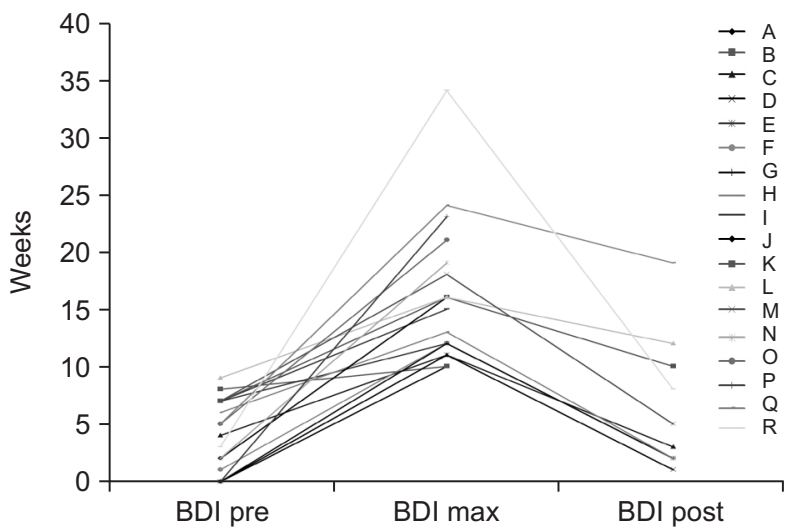

B

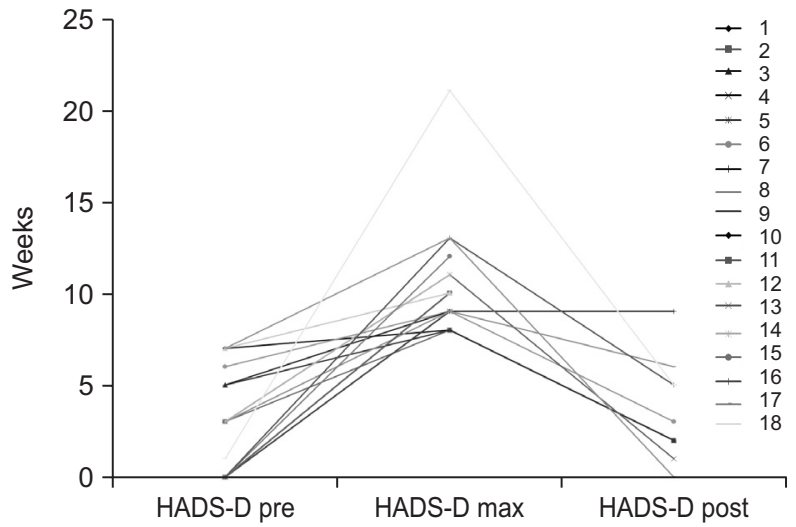

Fig. 1. Development of depression during antiviral treatment. Depressive symptoms developed in $34.6 \%(n=18)$ with a BDI-I score $\geq 10$ (A) and 29.5\% ( $\mathrm{n=18}$ ) with a HADS-D score $\geq 8$ (B) among 52 and 61 patients who had no depression at baseline, respectively. The point prevalence of moderate to severe depression (BDI-I score $\geq 16$ and HADS-D $\geq 11$ ) was $17.3 \%(n=9)$ according to the BDI-I score and $9.8 \%(n=6)$ according to the HADS-D score over the course of pegylated interferon and RBV therapy. The majority of patients exhibited increased BDI-I or HADS-D scores during treatment, which returned to normal after the completion of treatment.

BDI-I, Beck Depression Inventory-I; HADS-D, Hospital Anxiety and Depression scale-Depression.

A

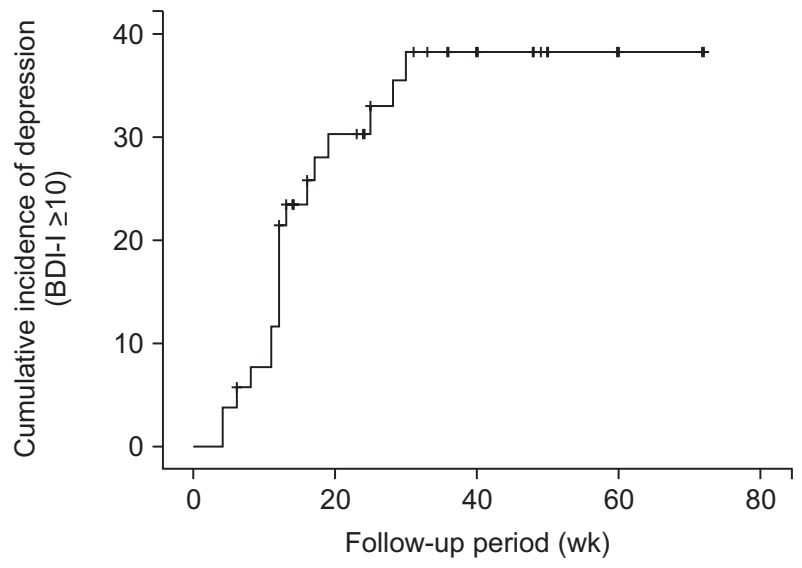

\begin{tabular}{lrrrr}
\hline FU period & 0 & 12 & 24 & 36 \\
\hline No. of Pt. at risk & 52 & 40 & 30 & 23 \\
$\%$ & 0 & 21.5 & 30.4 & 38.3 \\
\hline
\end{tabular}

B

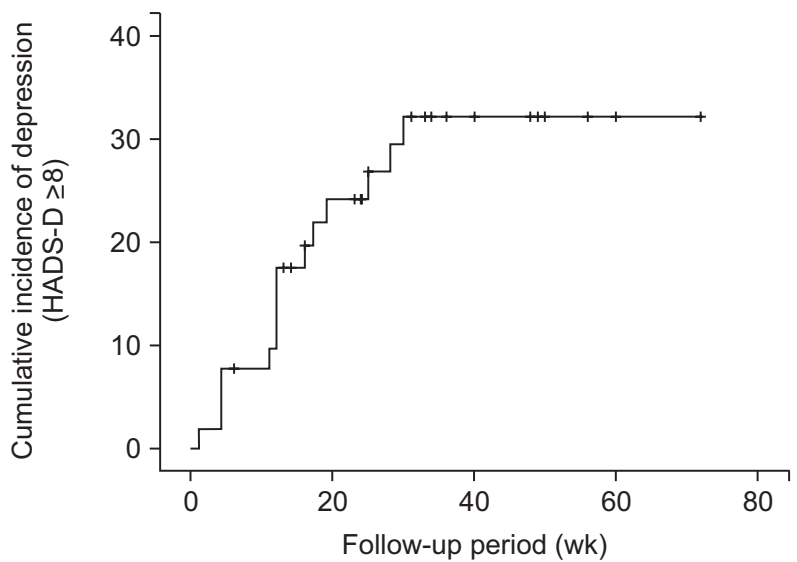

\begin{tabular}{lrrrr}
\hline FU period & 0 & 12 & 24 & 36 \\
\hline No. of Pt. at risk & 61 & 47 & 38 & 28 \\
$\%$ & 0 & 21.5 & 27.2 & 34.2 \\
\hline
\end{tabular}

Fig. 2. Cumulative incidence of depression during antiviral treatment with pegylated interferon $\alpha$ and ribavirin. The cumulative incidence rates of depression during antiviral therapy were $21.5 \%$ versus $21.5 \%$ at 12 weeks, $30.4 \%$ versus $27.2 \%$ at 24 weeks, $38.3 \%$ versus $34.2 \%$ at 36 weeks according to BDI-I (A) versus HADS-D (B), respectively.

BDI-I, Beck Depression Inventory-I; HADS-D, Hospital Anxiety and Depression scale-Depression; FU, follow-up; Pt., patients.

different epidemiology and patient's characteristics may be the reason, especially IVDU experience was very low (only 3\%) in our subjects, revealing a marked difference from Western patients. IVDU was highly associated with depression or other psychiatric problems.

Our patients with pretreatment depression showed a higher rate of unmarried state, reflecting marital function as a social support, which was compatible with a previous study. ${ }^{15}$ Because the major risk factor for HCV infection in Korea was health-care related rather than IVDU, this may be related to the predictor of depression as well as prevalence of depression.

In this study, 34.6\% by BDI-I or 29.5\% by HADS-D of depression-free patients at pretreatment developed depression during PR therapy. An Asian study in Japan ${ }^{20}$ using the BDI-II reported that the incidence of depression during PR therapy increased from $0 \%$ at baseline to $21 \%$ at 4 weeks and $34 \%$ at 12 weeks 
Table 4. Comparison of Clinical Variables between Patients Who Developed (BDI-I $\geq 10)$ and Did Not Develop (BDI-I <10) Depression during Pegylated Interferon and Ribavirin Therapy $(\mathrm{n}=52)$

\begin{tabular}{|c|c|c|c|}
\hline Variable & $\begin{array}{c}\text { Depression } \\
(B D I-I \geq 10, n=18)\end{array}$ & $\begin{array}{c}\text { No depression } \\
(\text { BDI-I }<10, n=34)\end{array}$ & $\mathrm{p}$-value \\
\hline Age, yr & $51.89 \pm 9.0$ & $53.74 \pm 9.5$ & 0.532 \\
\hline Male sex & $9(50.0)$ & 24 (70.6) & 0.226 \\
\hline BMI, kg/m² & $25.0 \pm 4.0$ & $24.0 \pm 2.9$ & 0.269 \\
\hline$\geq 25$ & $9(50.0)$ & $12(35.3)$ & 0.309 \\
\hline Education, $\geq$ high school & $14(82.4)$ & $22(66.7)$ & 0.247 \\
\hline Marital status, married & $17(100.0)$ & 31 (93.9) & 0.305 \\
\hline Current or former alcohol intake & $12(66.7)$ & $21(63.6)$ & 0.830 \\
\hline Current or former smoking & $12(66.7)$ & $16(47.1)$ & 0.245 \\
\hline Intravenous drug user, yes & 0 & 0 & - \\
\hline Past history of depression, yes & 0 & 0 & - \\
\hline Chronic hepatitis in diagnosis & $16(88.9)$ & $23(67.6)$ & 0.096 \\
\hline HCV genotype 1 & $7(38.9)$ & $10(33.3)$ & 0.700 \\
\hline Previous antiviral treatment & $12(66.7)$ & $22(64.7)$ & 0.889 \\
\hline WBC, $\mathrm{mm}^{3}$ & $4,597.8 \pm 1,440.2$ & $4,902.4 \pm 2,037.1$ & 0.908 \\
\hline Hemoglobin, g/dL & $13.5 \pm 1.5$ & $14.1 \pm 1.8$ & 0.317 \\
\hline Platelet, $\times 1,000 / \mathrm{mm}^{3}$ & $167.752 \pm 56.954$ & $174.9 \pm 65.6$ & 0.878 \\
\hline Prothrombin time, INR & $1.03 \pm 0.10$ & $1.06 \pm 0.08$ & 0.353 \\
\hline Albumin, g/dL & $4.3 \pm 0.4$ & $4.2 \pm 0.4$ & 0.658 \\
\hline Total bilirubin, mg/dL & $0.9 \pm 0.3$ & $1.0 \pm 0.4$ & 1.000 \\
\hline Creatinine, $\mathrm{mg} / \mathrm{dL}$ & $0.8 \pm 0.3$ & $0.8 \pm 0.2$ & 0.353 \\
\hline HCV RNA level, $\log _{10} \mathrm{IU} / \mathrm{mL},(3 / 29)$ & $4.84 \pm 0.98$ & $5.23 \pm 1.48$ & 0.144 \\
\hline AST, IU/L & $60.82 \pm 53.85$ & $59.68 \pm 45.92$ & 0.944 \\
\hline ALT, IU/L & $67.24 \pm 85.71$ & $60.24 \pm 38.62$ & 0.280 \\
\hline SVR & $10(55.6)$ & $29(85.3)$ & 0.020 \\
\hline Treatment discontinuation & $5(27.8)$ & $1(2.9)$ & 0.008 \\
\hline Depression as the reason of treatment discontinuation & $1(20.0)$ & 0 & 0.655 \\
\hline Post treatment BDI-I score, $\geq 10$ & $3(30.0)$ & 0 & 0.008 \\
\hline
\end{tabular}

Data are presented as mean \pm SD or number (\%).

BDI-I, Beck Depression Inventory-I; BMI, body mass index; HCV, hepatitis C virus; WBC, white blood cell; INR, international normalized ratio; AST, aspartate aminotransferase; ALT, alanine aminotransferase; SVR, sustained virologic response.

of PR therapy, which is quite similar to our study results. These depression incidences throughout PR therapy seem to resemble results from many preceding studies in other countries, e.g., $35 \%$ to $55.7 \%$ (USA) ${ }^{5,15,16} 27 \%$ (Austria), ${ }^{6} 36.7 \%$ to $41 \%$ (Italy), ${ }^{21,22}$ $20 \%$ to $44 \%$ (Japan), ${ }^{20,23}$ and 28\% (India). ${ }^{24}$ The depression development group in this study showed a significantly lower treatment completion rate and lower SVR rate.

Predictors for the development of depression during PR therapy in previous studies were a history of depression, low social support, history of alcohol usage, history of intravenous drug usage, history of major depression and ribavirin dosage assignment. ${ }^{7,15,25-28}$ However, we did not find any significant variables related to development of depression, probably because of small sample size and different subject characteristics.

We used two scales for the screening of depression (BDI-I score and HADS-D score), and baseline depression prevalence was not concordant between the two scales: $17.6 \%$ versus $4.3 \%$ measured by BDI-I score and HADS-D score, respectively. If the BDI-I cutoff level were set at 16 rather than 10 , the moderate to severe depression rate was 7.6\%, which was similar to the $4.3 \%$ of the HADS-D for depression. The BDI scale is frequently used in studies on depression in medical illness including HCV, but it contains several somatic symptoms of chronic illness such as fatigue, sleep difficulty and appetite changes, therefore, false positive detection of depression could occur, despite the high sensitivity and high negative predictive value. ${ }^{25,29}$ In contrast, HADS was developed to exclude both somatic components and serious mental symptoms which were less common in patients attending non-psychiatric clinics. The sensitivity and specificity for both HADS-A and HADS-D were approximately 0.8 . 


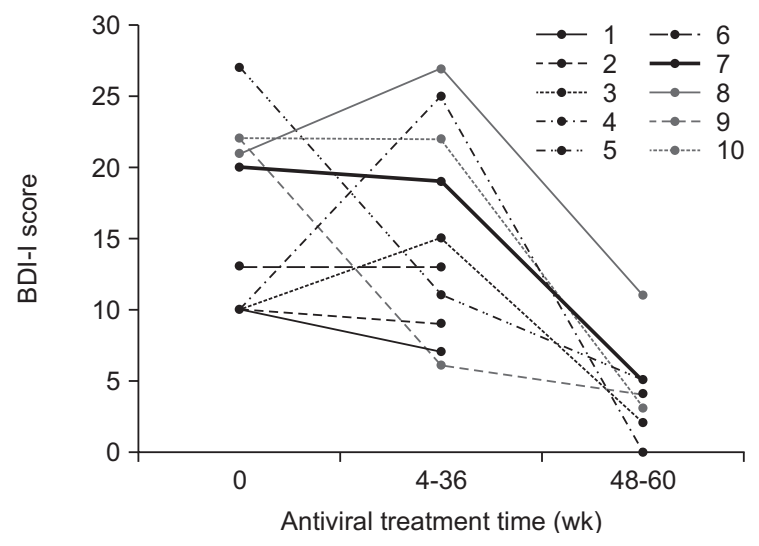

Fig. 3. Changes in the Beck Depression Inventory-I (BDI-I) score during pegylated interferon and ribavirin therapy among patients with underlying depression at baseline. Seven patients with pretreatment depression showed aggravation of the BDI-I score during antiviral therapy, and two patients (number 2 and number 10) received antidepressant therapy. Moreover, one patient did not recover after 6 months from the end of pegylated interferon $\alpha$ and ribavirin therapy.

The correlation coefficients between the HADS and BDI were reported as 0.62 to 0.73 , which was concordant with our study results (the Spearman's rank correlation coefficient between the BDI-I score and the HADS-D score was 0.66, data not shown). ${ }^{13}$

This study has some limitations. First, it was based on selfreported surveys which could be biased with lack of more stringent psychiatric exclusion criteria for depression. However, such surveys remain the practical way to evaluate patient-reported outcomes. Second, though the subjects were enrolled in three hospitals, the sample size is relatively small, and external validation may be required to represent overall Korean patients. Third, not all patients responded to the survey at the planned time points.

In conclusion, the prevalence of depression in Korean CHC patients seems to be low compared to Western patients, however, the incidence of depression during PR therapy (about 30\%) was similar to that of other populations, which led to a lower SVR rate. Active screening and multidisciplinary management of depression in CHC patients during interferon-based therapy is warranted, which will be overcome by direct acting antiviral therapy in near future.

\section{CONFLICTS OF INTEREST}

No potential conflict of interest relevant to this article was reported.

\section{ACKNOWLEDGEMENTS}

This study was supported by a grant for the Chronic Infectious Disease Cohort Study (Korea HCV Cohort Study, 48004859-304) from the Korea Centers for Disease Control and Prevention. The authors are indebted to J. Patrick Barron, Professor
Emeritus, Tokyo Medical University and Adjunct Professor, Seoul National University Bundang Hospital for his editing of this manuscript.

\section{REFERENCES}

1. Adinolfi LE, Nevola R, Lus G, et al. Chronic hepatitis C virus infection and neurological and psychiatric disorders: an overview. World J Gastroenterol 2015;21:2269-2280.

2. Conversano C, Carmassi C, Carlini M, Casu G, Gremigni P, Dell'Osso L. Interferon alpha therapy in patients with chronic hepatitis C infection: quality of life and depression. Hematol Rep 2015;7:5632.

3. Asnis GM, De La Garza R 2nd. Interferon-induced depression in chronic hepatitis C: a review of its prevalence, risk factors, biology, and treatment approaches. J Clin Gastroenterol 2006;40:322335.

4. Huckans M, Fuller B, Wheaton V, et al. A longitudinal study evaluating the effects of interferon-alpha therapy on cognitive and psychiatric function in adults with chronic hepatitis C. J Psychosom Res 2015;78:184-192.

5. Chapman J, Oser M, Hockemeyer J, Weitlauf J, Jones S, Cheung R. Changes in depressive symptoms and impact on treatment course among hepatitis $C$ patients undergoing interferon- $\alpha$ and ribavirin therapy: a prospective evaluation. Am J Gastroenterol 2011;106:2123-2132.

6. Stewart B, Mikocka-Walus A, Morgan J, et al. Anxiety and depression in Australian chronic hepatitis C outpatients: prevalence and predictors. Australas Psychiatry 2012;20:496-500.

7. Boscarino JA, Lu M, Moorman AC, et al. Predictors of poor mental and physical health status among patients with chronic hepatitis $\mathrm{C}$ infection: the Chronic Hepatitis Cohort Study (CHeCS). Hepatology 2015;61:802-811.

8. Seong MH, Kil H, Kim YS, et al. Clinical and epidemiological features of hepatitis C virus infection in South Korea: a prospective, multicenter cohort study. J Med Virol 2013;85:1724-1733.

9. Kim JY, Cho J, Hwang SH, et al. Behavioral and healthcare-associated risk factors for chronic hepatitis C virus infection in Korea. J Korean Med Sci 2012;27:1371-1377.

10. Beck AT, Ward CH, Mendelson M, Mock J, Erbaugh J. An inventory for measuring depression. Arch Gen Psychiatry 1961;4:561571.

11. Holtzheimer PE, Veitengruber J, Wang CC, et al. Utility of the Beck Depression Inventory to screen for and track depression in injection drug users seeking hepatitis $\mathrm{C}$ treatment. Gen Hosp Psychiatry 2010;32:426-432.

12. Shin MS, Kim ZS, Park. KB. The cut-off score for the Korean version of Beck Depression Inventory. Korean J Clin Psychol 1993;12:71-81.

13. Bjelland I, Dahl AA, Haug TT, Neckelmann D. The validity of the Hospital Anxiety and Depression scale: an updated literature review. J Psychosom Res 2002;52:69-77. 
14. Weinstein AA, Kallman Price J, Stepanova M, et al. Depression in patients with nonalcoholic fatty liver disease and chronic viral hepatitis B and C. Psychosomatics 2011;52:127-132.

15. Evon DM, Ramcharran D, Belle SH, et al. Prospective analysis of depression during peginterferon and ribavirin therapy of chronic hepatitis C: results of the Virahep-C study. Am J Gastroenterol 2009;104:2949-2958.

16. Fireman M, Indest DW, Blackwell A, Whitehead AJ, Hauser P. Addressing tri-morbidity (hepatitis C, psychiatric disorders, and substance use): the importance of routine mental health screening as a component of a comanagement model of care. Clin Infect Dis 2005;40 Suppl 5:S286-S291.

17. el-Serag HB, Kunik M, Richardson P, Rabeneck L. Psychiatric disorders among veterans with hepatitis $C$ infection. Gastroenterology 2002;123:476-482.

18. Lee K, Otgonsuren M, Younoszai Z, Mir HM, Younossi ZM. Association of chronic liver disease with depression: a populationbased study. Psychosomatics 2013;54:52-59.

19. Wang Z, Du J, Zhao M, Page K, Xiao Z, Mandel JS. Hepatitis C virus infection is independently associated with depression among methadone maintenance treatment heroin users in China. Asia Pac Psychiatry 2013;5:191-196.

20. Nomura H, Miyagi Y, Tanimoto H, Yamashita N, Oohashi S, Nishiura S. Occurrence of clinical depression during combination therapy with pegylated interferon alpha or natural human interferon beta plus ribavirin. Hepatol Res 2012;42:241-247.

21. Mangia A, Ricci GL, Persico M, et al. A randomized controlled trial of pegylated interferon alpha-2a (40 KD) or interferon alpha-2a plus ribavirin and amantadine vs interferon alpha-2a and ribavirin in treatment-naïve patients with chronic hepatitis C. J Viral Hepat
2005;12:292-299.

22. Bonaccorso S, Marino V, Biondi M, Grimaldi F, Ippoliti F, Maes M. Depression induced by treatment with interferon-alpha in patients affected by hepatitis C virus. J Affect Disord 2002;72:237-241.

23. Miyaoka H, Otsubo T, Kamijima K, Ishii M, Onuki M, Mitamura $\mathrm{K}$. Depression from interferon therapy in patients with hepatitis C. Am J Psychiatry 1999;156:1120.

24. Mahajan S, Avasthi A, Grover S, Chawla YK. Role of baseline depressive symptoms in the development of depressive episode in patients receiving antiviral therapy for hepatitis C infection. J Psychosom Res 2014;77:109-115.

25. Medeiros LP, Kayo M, Medeiros RB, Lima MB, Mello CE. Interferon-induced depression in patients with hepatitis C: an epidemiologic study. Rev Assoc Med Bras (1992) 2014;60:35-39.

26. Armstrong GL, Wasley A, Simard EP, McQuillan GM, Kuhnert WL, Alter MJ. The prevalence of hepatitis C virus infection in the United States, 1999 through 2002. Ann Intern Med 2006;144:705714.

27. Raison CL, Borisov AS, Broadwell SD, et al. Depression during pegylated interferon-alpha plus ribavirin therapy: prevalence and prediction. J Clin Psychiatry 2005;66:41-48.

28. Liu SS, Schneekloth TD, Talwalkar JA, et al. Impact of depressive symptoms and their treatment on completing antiviral treatment in patients with chronic hepatitis C. J Clin Gastroenterol 2010;44:e178-e185.

29. Patterson AL, Morasco BJ, Fuller BE, Indest DW, Loftis JM, Hauser P. Screening for depression in patients with hepatitis $C$ using the Beck Depression Inventory-II: do somatic symptoms compromise validity? Gen Hosp Psychiatry 2011;33:354-362. 